\title{
HF Radar role in an Integrated Ocean Observing System
}

\author{
M.L.Heron and A.Prytz \\ Australian Coastal Ocean Radar Network \\ Marine Geophysical Laboratory \\ James Cook University \\ Townsville, Australia 4811
}

\begin{abstract}
The Australian Coastal Ocean radar Network (ACORN) is a monitoring network of HF radars which are being installed around Australia under a National Collaborative Research Infrastructure Strategy (NCRIS). It is a five-year project, at the end of which there will be five pairs of radar stations and one triplet installed and operating, enabled by the central pool of funding for the Integrated Marine Observing System (IMOS) which is a part of NCRIS, and augmented by funding from other sources. At each chosen site there is a pair (or triplet) of radar stations, mounted on the shore, which receive radar echoes from the rough sea. The two stations provide a triangulation which enables the data analysis software to extract surface currents, wave heights and directional wave spectra over the coastal ocean. The NCRIS strategy is to support research into coastal dynamics and exchange between the open ocean and the continental shelf. Research is being undertaken into the use of maps of surface currents, well resolved in time and space, in mixing of different bodies of water, physical connectivity between reefs and islands, and nowcasting and short-term forecasting of surface currents. There is potential for application of the data to management of coastal marine resources, and in marine safety areas. Real-time maps of surface currents and the prospect of short-term forecasting have the potential to reduce search areas in coastal waters and to make pollution/spill mitigation more effective. With the establishment of $\mathrm{HF}$ radar monitoring stations like those in ACORN, there is growing opportunity for researchers around the world to access data from well curated archives to carry out basic research on physical oceanography, or applications research without having direct access to the measuring facility. One of the features of IMOS is to establish such an archive which is easy to access and free to research users. This feature brings the ACORN HF radars into GEOSS for coastal processes and dynamics.
\end{abstract}

\section{NCRIS/IMOS/ACORN STRUCTURE AND GOALS}

The Australian Federal Department of Science, Industry, Innovation and Research has established a National Collaborative Research Infrastructure Strategy (NCRIS) to encourage the organization of research data into properly curated archives which are easily and freely available to researchers. NCRIS covers a wide range of basic research, and one of its ten major capabilities is the Integrated Marine Observing System (IMOS). IMOS was formed through a grass-roots process in which the Australian marine research community were asked to contribute their vision of the types of ocean observations which should go into such an archive.

\section{The Australian Coastal Ocean Radar Network (ACORN)}

The core of the Australian Coastal Ocean Radar Network (ACORN) consists of three HF radar pairs and one triplet, which are being deployed at various points around the Australian coastline. ACORN includes phased array, beamforming technology as well as the small footprint, amplitude direction-finding technology, in order to offer maximum flexibility in site selection, and availability of a wide range of monitored parameters. Two other HF radar systems, one in the Great Barrier Reef and one in South Australia, are being acquired by funds outside the IMOS capital budget and are managed by ACORN in return for the data being delivered to the IMOS archive. The sites for the first series of deployments (three pairs and one triplet) are shown in Fig. 2 as red stars, and the yellow stars show the locations of the last two sites in the ACORN programme. The first approved installations are around Heron Island in the Capricorn and Bunker Groups on the Great Barrier Reef, west of Kangaroo Island in the Southern Ocean, and the north side of Perth in the Indian Ocean.

The data are being routed through a central laboratory for quality assurance and metadata labelling. System diagnostic data are also being sent to the central laboratory and all monitoring and maintenance originate there. The maintenance model is a combination of caretaker casual staff at each site, with full technical competence at the central laboratory. The main advantage of this centralised model is that it ensures that the data are archived in a consistent way. There is a need to build capacity and expertise around the country, and discussion is underway to determine the relative emphasis which should be placed on technical expertise and on applications expertise, and science. Deployment of the radars is in support of IMOS regional nodes where there is a range of identified questions concerned with boundary currents and associated eddies and their interactions with shelf water and topography. In turn these are linked to productivity, connectivity of biological populations and phenomena such as coral bleaching and diseases. In most cases the use of HF radars will be complemented by data from regional moorings and by the fleet of unmanned gliders. The radar network will provide a basis for applied research in wave prediction and will offer test sites for hydrodynamic modelling. 


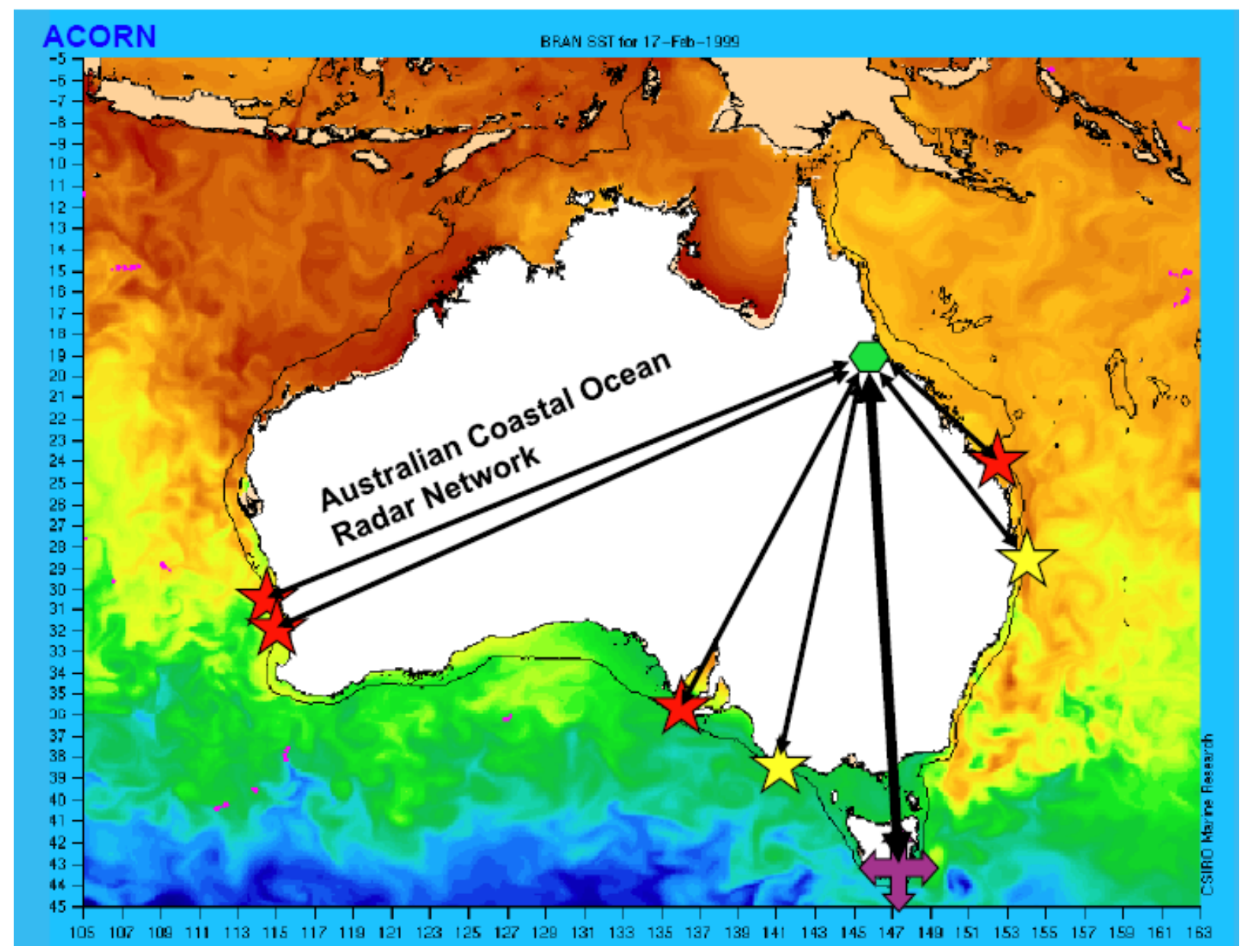

Figure 1. Initial deployments of three pairs and one triplet HF radar systems. The field sites are marked with red stars, the location of the data and maintenance laboratory is green and the IMOS archive centre has the purple cross. The yellow stars mark the positions of the final two station pairs. The background sea surface temperature map is a product from CMAR's BLUELINK computer model [1].

\section{III. $\quad$ HF Radar: Sea Surface Parameters}

The main product from the HF radar is the map of surface currents. With the configuration at the GBR site we produce a map of surface currents every 10 minutes on a 4 x $4 \mathrm{~km}$ grid over an area of about $150 \mathrm{~km} \times 150 \mathrm{~km}$. One such 10-minute grab is shown in Fig. 2 for the GBR radar system. These surface current maps will be archived with quality assurance indices on each data point. Surface current components are measured as radial components along the line from the grid point to the radar station and are derived from the frequency of the first-order peaks in the Doppler spectra of radar echoes. Because it is based on a frequency standard, the precision of these data is generally very good. Significant wave heights and wind directions are also produced every 10 minutes on the same grid. Significant wave heights are derived from the ratio of energy in the second-order continuum surrounding the Bragg peaks in the
Doppler spectra of radar echoes, to the energy in the adjacent Bragg peak.

\section{IV. \\ ACORN Data Archive}

We have identified four levels for archiving data from the ACORN network of HF ocean radars. Level 0 is for raw data in proprietary format consisting of time series of in-phase and quadrature amplitudes of base-band signals at each of the receive antennas. These data are for re-processing or technology development research and are very large files which will be deeply archived and available only on request. At the other end of the scale are Level 3 data which are smoothed visualisations of hourly values of the parameters with access tools to extract movie loops and a high standard of graphical presentation. The levels of data archive are described in Table 1. 


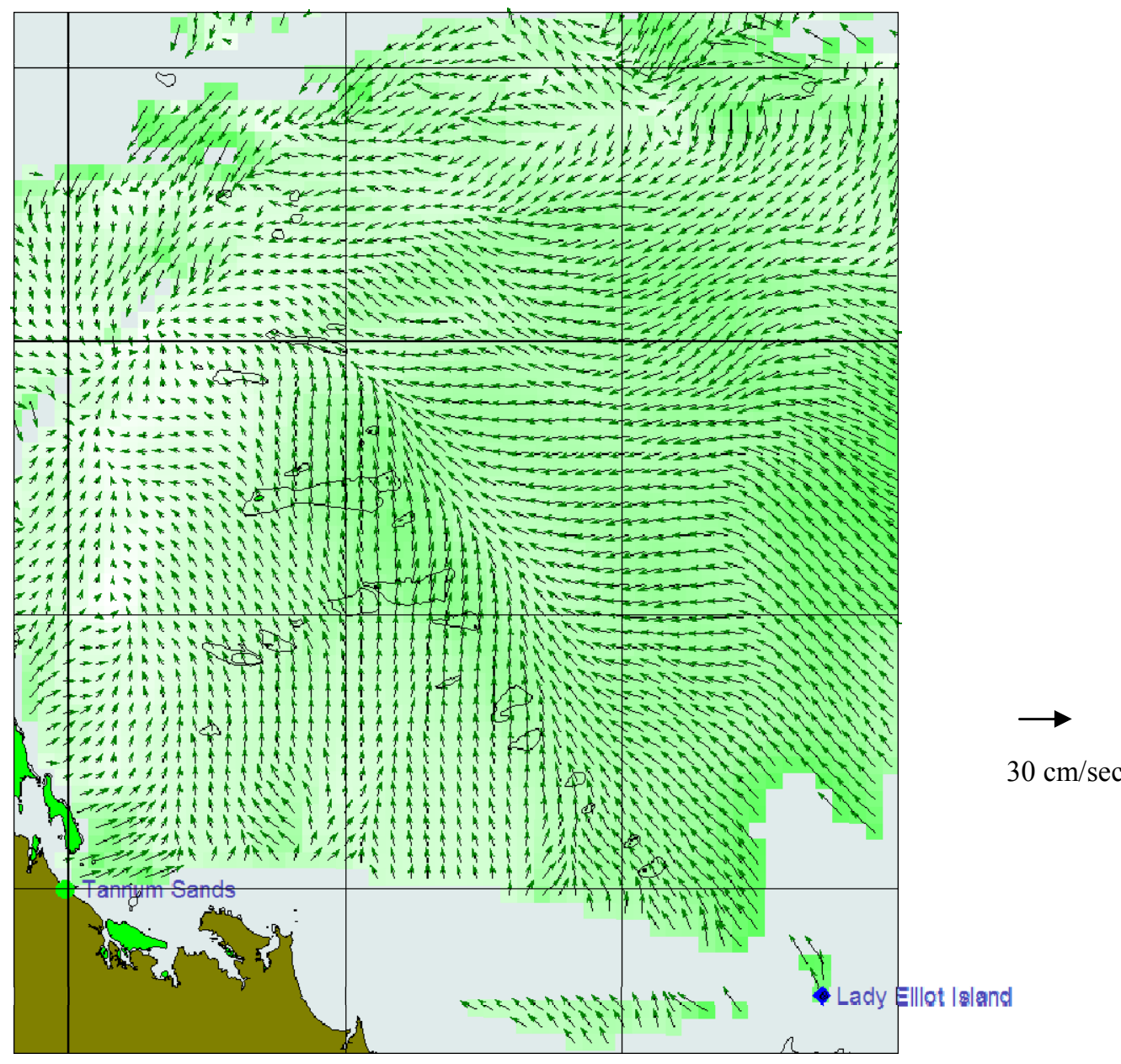

Figure 2. A 10-minute grab of surface current data from the GBR radar system. The data points are not smoothed in time or space, and are untouched data from the real-time processor. The marked grid lines are spaced $50 \mathrm{~km}$ apart.

Each data value comes with a quality index which is defined in the metadata. Metadata are included in each file. The format being followed is netCDF in order to facilitate data discovery. There are numerous netCDF conventions that one can follow and the one we use is compatible with the metadata standard defined by ISO19115 and the AODC Marine Community Profile based on that standard. It is impractical to manually enter metadata records into the archive for each of our files; these are produced every 10 min per station, with at least 3 files per 10 min interval. Our files thus needed to be in a format that allows the relevant metadata to be harvested automatically when the files are uploaded to the archive.

\section{Potential Research and Operational Applications}

Obviously the users who will benefit most from the archived data from the ACORN HF radars are those who are investigating coastal ocean dynamics in the areas covered by the radars. These are mostly operational maritime applications like pollution drift, search and rescue, and coastal management. There are some areas of research which, while carried out in the area covered by the radar, have wider applications in areas not covered by the HF radar. These are mostly calibration investigations like evaluating parameterisations of small scale effects in hydrodynamic modelling, evaluating algorithms for analysing satellite data on the continental shelf, and validating numerical models.

This last category is significant because it offers an opportunity for collaborative research which might involve researchers from any community in the world, and deliver research outcomes which are of global value.

There are some fundamental questions that can be addressed by using HF radar data when no other technology will be as useful. One of these, for example, is in measuring and 
Table 1. Parameters and their archive levels. The storage is given per day for a two-station site. Storage space for the Level 3 products is not given because this will vary according to the access tools which are provided at the archive exit.

\begin{tabular}{|c|c|c|c|c|}
\hline & Level 3 & Level 2 & Level 1 & Level 0 \\
\hline Surface Currents & maps, movies & $\begin{array}{l}\text { One hour averages; } \\
\text { speed \& Direction } \\
16 \mathrm{MB} / \text { day }\end{array}$ & $\begin{array}{l}10 \mathrm{~min} \text {; radial } \\
\text { components to each } \\
\text { station. } \\
52 \mathrm{MB} / \text { day }\end{array}$ & \\
\hline Significant wave height & maps, movies & $\begin{array}{l}\text { One hour averages; } \\
\text { scalar values at grid } \\
\text { points. } \\
10 \mathrm{MB} / \text { day }\end{array}$ & $\begin{array}{l}10 \mathrm{~min} \text {; Ratio of } \\
\text { second-order to first- } \\
\text { order energy for each } \\
\text { station } \\
52 \mathrm{MB} / \text { day } \\
\end{array}$ & \\
\hline Wind Direction & maps, movies & $\begin{array}{l}\text { One hour averages; } \\
\text { scalar values at grid } \\
\text { points. } \\
10 \mathrm{MB} / \text { day }\end{array}$ & $\begin{array}{l}10 \mathrm{~min} \text {; Ratio of } \\
\text { energy in the two first- } \\
\text { order lines for each } \\
\text { station. } \\
26 \mathrm{MB} / \text { day }\end{array}$ & \\
\hline Dominant wave period & maps, movies & $\begin{array}{l}\text { One hour averages; } \\
\text { scalar values at grid } \\
\text { points. } \\
10 \mathrm{MB} / \text { day }\end{array}$ & & \\
\hline Raw Time Series & & & & $\begin{array}{l}\text { Phase \& quadrature at } \\
\text { each receive antenna } \\
\text { for each station. } \\
3 \mathrm{~GB} / \text { day }\end{array}$ \\
\hline
\end{tabular}

evaluating Stokes Drift as an integral part of the surface current. Mao and Heron [2] have shown that HF radar can separately measure the Stokes wave-driven current and the wind-stress effect which produces and Ekman current. Ardhuin et al. [3] carried out a more comprehensive study but more work needs to be done to validate the parameterisation of air-sea coupling into the circulation models.

\section{VI.}

\section{Conclusion}

The Australian Coastal Ocean Radar Network is being established as a development of research infrastructure in Australian coastal waters. The sites have been chosen because of research challenges in those areas, and generally they are associated with the deployment of other equipment like acoustic current profilers and wave measuring buoys. The data are archived centrally in a way that is easily accessed and essentially free for research use. Some research and operational applications are restricted to the specific sites of the deployments, but there are many research challenges of a more general nature which can be addressed using these data, but which apply globally to other locations. Some of the potential research is of a fundamental nature and not connected with any specific measuring site.

With large data archives like this, and other IOOS archives, there are increasing opportunities for researchers to participate in research projects without the need to own expensive equipment items.

\section{ACKNOWLEDGMENT}

The Australian Coastal Ocean Radar Network is a facility of the Integrated Ocean Monitoring System within the National Collaborative Research Strategy of the Australian Commonwealth.

\section{REFERENCES}

[1] $<$ http://www.cmar.csiro.au/bluelink/>

[2] Mao, $Y$ and M.L.Heron, The influence of fetch on the response of surface currents to wind studied by HF ocean surface, J. Phys. Oceanography, 38, 1107-1121, 2008.

[3] Arduin, F., L. Marie, N. Rascle, P. Forget and A/ Rolnd, Observation and estimation of Lagrangian, Stokes and Eulerian currents induce dby wind ad waves on the sea surface, J. Phys. Oceanography, 38, October 2008. 